\title{
Attachment Dimensions as Moderators of the Relationship between Commitment to Supervisors and Organizational Citizenship Behavior
}

\author{
Milica Schraggeová (D) Zuzana Stupková \\ Department of Psychology, Faculty of Arts, Comenius University in Bratislava
}

\begin{abstract}
The aims of this study are to examine the correlation between the commitment to supervisors and Organizational Citizenship Behavior (OCB) by using two different commitment conceptions and to determine whether this relationship is moderated by personal internal attachment dimensions. The theoretical framework was provided by the concept of Affective Commitment (AC), derived from Meyer and Allen's Three-Component Model (TCM), the target-free approach of Klein et al. (2014), and attachment personality theory. The study used the Affective Commitment to Supervisors (ACS) scale and Klein's Unidimensional and Target-free (KUT) scale. The predictive value of supervisory commitment was confirmed by both methods. However, depending on the scale, the results revealed different links between commitment, OCB, and attachment personal dimensions as moderating factors. The ACS scale interacted with the dimension of attachment anxiety: In the case of a low or moderate supervisory commitment, anxiety decreased engagement in OCB. By contrast, the moderating model indicated that there was no such interaction when using the KUT scale.
\end{abstract}

Key words: Affective Commitment to Supervisors, target-free commitment, internal attachment dimension, Organizational Citizenship Behavior

\section{Introduction}

Organizations want to have dedicated employees who identify with the organization, its values, and goals, and who have good relationships with colleagues and supervisors. This may explain why researchers and prac- titioners have been paying attention to the concept of commitment as the key factor in understanding positive behavior and attitudes in the workplace for over fifty years (Klein et al., 2012; Meyer, 2009; van Rossenberg et al., 2018). Commitment was mostly explored as an antecedent of two behavioral categories: focal behaviors (e.g., turnover) and discre-

Correspondence concerning this article should be addressed to Milica Schraggeová, Department of Psychology, Faculty of Arts, Comenius University in Bratislava, Slovak Republic.

E-mail: milica.schraggeova@uniba.sk

Received January 15, 2020 
tionary examples of organizational citizenship behavior (OCB) (Meyer \& Herscovitch, 2001). Many studies and meta-analyses have confirmed that committed employees perform better, show higher levels of organizational citizenship behavior, are more satisfied at work, and have a lower tendency to leave the organization (Meyer et al., 2002; Meyer \& Herscovitch, 2001; Vandenberghe \& Bentein, 2009; Van Steenbergen \& Ellemers, 2009; Wang, 2010). Commitment research initially focused on the organization, seeing it as the key entity behind employee behaviors (Meyer \& Allen, 1991; Mowday et al., 1979). However, employees develop an attachment and commitment to multiple workplace foci both within an organization (e.g., supervisors, work teams, and co-workers) as well as outside of it (e.g., clients). This is why scholars emphasize the need to pay attention to different targets of commitment, which would allow for a description of various forms of work behavior in a more specific way (Becker, 2016; Becker et al., 1996; Klein et al., 2012; Meyer \& Herscovitch, 2001; Reichers, 1985). Among the various targets of commitment, commitment to a career (Goulet \& Singh, 2002), profession (Blau, 2003), work team (Rikketa \& Van Dick, 2005), and supervisor (Vandenberghe \& Bentein, 2009) are most often examined.

The most frequently studied type of employee commitment has been affective commitment to organizations, defined as an emotional attachment to an organization that is close to identification and devotion (Meyer et al., 2002; Meyer \& Allen, 1997). Some authors point to the central role of affective commitment to supervisors in relation to the behavior and attitudes of employees (Askew, 2013; Chughtai, 2013). They argue that supervisors are formal authorities that monitor and manage their subordinates, and that employees tend to act in accordance with a supervisor's requirements and feedback (Eisenberger et al., 2002). Research suggests that supervisory commitment has a direct impact on organizational citizenship (Cheng et al., 2003), affects performance more positively than organizational commitment (Becker et al., 2006; Vandenberghe et al., 2004), and affects the level of one's well-being and intention to stay (Landry et al., 2010).

Despite considerable knowledge about the impact of commitment to organizations and to supervisors on work behavior, little is known about the role of personality dispositions on these relationship effects. An important aim of this study is to examine the moderating influence of personality dimensions - derived from the attachment working model based on John Bowlby's theory - on the interaction between supervisory commitment and organizational citizenship behavior. The study's focus is on commitment to supervisors as an interpersonal bond between supervisors and followers, which can more significantly evoke the models of individuals' inter-term functioning than their commitment to organizations. As mentioned above, it has already been determined that affective commitment between supervisors and employees positively affects engagement in prosocial behavior, represented by organizational citizenship behavior, but it is assumed that this relationship may be significantly influenced by the internal concept of attachment working models (anxiety and avoidance). From a higher perspective, this study aims to help understand the complex mechanisms of behavior that can lead to the improvement of individual and organizational performances and organizational goals.

The first part of this study briefly reviews the main aspects of commitment research, and it explains the connection between commitment and organizational citizenship behaviors. It also introduces attachment working models in light of supervisor-follower bonds in the work context. In the subsequent 
part, the research hypothesis is introduced and the research results are presented.

\section{Commitment to Organizations and to Supervisors}

Researchers' interest in commitment can be traced back to the 1960s (Becker, 1960), when a calculative (or instrumental) approach to understanding commitment was dominant. According to Becker's side-bet theory, commitment develops as a result of economic thinking and calculating decisions, and is formed by the accumulation of benefits gained over a long period of time. Becker's perspective is also transactional, as commitment arises from the exchange between an individual's investment in an organization and subsequent rewards from the employer (Mercurio, 2015). In the 1970s and 1980s, an attitude-based approach to commitment prevailed, offering an understanding of commitment as a process that begins with a certain way of thinking or a mindset. Employees initially consider their relationship with the organization (or other work object), followed by a willingness to behave in favor of it (or another object) (Mowday et al., 1979; Reichers, 1985). In the 1990s, Meyer and Allen's Three-Component Model (TCM) became the most influential model in commitment research. Meyer and Allen (1991) believe that commitment is a mindset that can manifest as a desire, need, or obligation to maintain employment in an organization, thus constituting three forms of commitment: 1) affective - referring to an employee's emotional attachment to, identification with, and involvement in an organization; 2) normative - referring to an employee's moral duty to stay loyal to an employer; and 3) continuance - referring to an employee's attachment to an organization based on the perceived costs associated with leaving it as well as an awareness of the lack of alternative employment opportunities outside the organization. Organization commitment research has focused on the prediction of work behavior, particularly employees' turnover intention, actual turnover, performance, absenteeism, stress, well-being, and organizational citizenship behavior (Meyer et al., 2002).

Although Meyer and Herscovitch (2001) revised the three-component organization commitment model to other targets, scholars have criticized it for overlapping with related constructs (Klein et al., 2012; Solinger et al., 2008). Another point of criticism was the considerable overlap (repeatedly high correlations) between affective and normative commitment both empirically and theoretically (Jaros, 2007, 2017). In their meta-analytical study, Meyer et al. (2002) summarize that normative and affective commitment are highly correlated with each other and have many common antecedents and consequences. Klein et al. (2012) introduced a fundamental reconceptualization of commitment. They call attention to the fact that the term "commitment" is used to refer to different bond types and advise in favor of reserving it for a particular type of bond, since the organizational commitment lens does not apply to other targets and the organization is not necessarily the primary commitment target (Klein et al., 2014).

Klein et al. (2012) redefined commitment, characterizing it as "a volitional psychological bond reflecting dedication to and responsibility for a particular target" (p. 137). As opposed to TCM, Klein et al. (2012) define commitment as unidimensional, universal, and thus applicable to a range of different targets. Targets can be various social entities (organizations or teams), people (co-workers or leaders), or goals (careers, tasks, and jobs). This is why they described their approach as "target-free," because it allows them to simultaneously examine multi- 
ple commitments and directly compare them. Through the unidimensional target-free commitment conception, Klein et al. (2012) aspired to bring clarity and consistency to research and its practical implications.

Landry et al. (2010) examined employees' commitment to supervisors; their regression analysis has shown that affective commitment to supervisor (ACS) is a better predictor of the studied consequences than other forms of supervisory commitment (normative and continuance), which is consistent with Meyer and Herscovitch's (2001) argument that the affective form of commitment has a wider range of influence on behavior than the other forms. Landry et al. (2014) discovered that ACS significantly reduced the occurrence of negative supervisor-subordinate interactions. Vandenberghe and Bentein (2009) found stronger links between affective commitment to supervisor and turnover intention in the case of employees with a lower organizational commitment. Where actual turnover was concerned, commitment to supervisors acted as the only significant predictor. Chen et al. (2002) analyzed the relationship between loyalty to supervisors/organizations and employee behavior in China. For them, loyalty was synonymous with commitment to supervisors. Results indicate that loyalty to supervisors was more strongly associated with two types of performance (in-role and extra-role) than commitment to organizations. Compared to the affective commitment to organizations, affective commitment to the supervisor was revealed to be more strongly related to turnover intention (Vandenberghe et al., 2017), task performance (Vandenberghe et al., 2004), and citizenship behavior (Askew et al., 2013). All these studies measuring commitment to supervisors used affective commitment scales derived from Meyer's and Allen's three-component model of commitment (TCM).

\section{Organizational Citizenship Behavior}

The relationship between organizational citizenship behavior (OCB) and organizational commitment has been documented in several studies (Allen et al., 2011; Cetin et al., 2015; Meyer et al., 2002), and it is necessary to discuss this concept in more detail. Extra-role marking behavior is most often a hidden form of OCB as volitional and non-obligatory behaviors with strong prosocial dimensions. More precisely, OCB has been defined as a kind of voluntary behavior that is not directly or explicitly recognized by a formal rewards system; it goes beyond the core tasks and aggregately benefits the effective functioning of the organization (Organ, 1988). Behaviors that are examples of citizenship at work are not critical to the job, but they do benefit and support co-workers while also encouraging a greater organizational efficiency (Podsakoff et al., 2009). Although OCB is a spontaneous and informal employee initiative, managers support and encourage employees to engage in such behavior (Organ et al., 2006). Podsakoff and MacKenzie (1997) emphasize that OCB is an important factor in the effectiveness of teamwork and organizations. Voluntary prosocial behavior primarily contributes to the performance of an organization through the formation of social capital, resulting in strong interpersonal bonds among employees (Bolino et al., 2003). Similarly, Organ stressed the supportive social context as the main characteristic of OCB "[...] that supports the social and psychological environment in which task performance takes place" (Organ, 1997, p. 95). OCB is not one unitary way of behaving; rather, it is a set or cluster of behaviors that benefits organizations, teams, or individuals (Allen et al., 2011). Organ (1988) proposed a distinction between five subdimensions of OCB and provided examples: altruism (help- 
ing co-workers without expecting anything in return); conscientiousness (going above and beyond by e.g., coming early into work to finish a project); sportsmanship (staying in good spirits even if things go wrong); courtesy (an employee is considerate or polite to those they work with); and civic virtue (representing the organization in a positive light and encouraging a sense of community). In their meta-analysis, Podsakoff et al. (2000) pointed out that there is no consensus among researchers concerning the number and types of OCB dimensions. Some scholars recommend avoiding a focus on specific dimensions and interpreting research results that define OCB as a latent general construct (Desivilya et al., 2006; LePine et al., 2002). Williams and Anderson (1991) attempted to distinguish between two types of citizenship behaviors depending on the object to which they are directed; specifically, OCBI refers to civic behavior directed toward other individuals, and OCBO refers to civic behavior toward the organization as a unit. In their meta-analysis, Podsakoff et al. (2009) examined the relationship between OCB and various consequences at both the individual and organizational levels. However, their results did not support the need to distinguish between the OCB targets proposed by Williams and Anderson (1991). The consequences of OCB were similar when they were directed at individuals or at organizations as a whole.

Bolino and Turnley (2003) summarized the main antecedents of OCB, such as job satisfaction, transformational and supportive leadership, job involvement, organizational support, trust, organizational justice, and psychological contract fulfillment. Personality characteristics that predispose certain individuals to be more likely to be involved in OCB are another type of precursor. Individuals scoring highly in conscientiousness, extraversion, optimism, the expression of team orientation, empathy, and altruism were inclined to exhibit a higher level of citizenship behavior (Bolino \& Turnley, 2003).

\section{Attachment Theory in the Context of Work}

Attachment theory represents a relatively new approach to the investigation of individual differences in behavior and attitudes at work and may be a suitable alternative to the predominant Five Factor Model (Harms, 2011). Bowlby's theory of attachment is based on the knowledge that early experiences with an attachment figure (a mother or another caregiver) are transformed into internal working models representing prototypical personality traits in adulthood (Bowlby, 2010). Repeated experiences with attachment figures lead to the development of internal working models and are characterized by three main aspects: 1) the working model of the self, 2) the working model of others, and 3) the working model of the relationship (Hazan \& Shaver, 1994). Primary attachment styles have been described by Ainsworth as secure, uncertainanxious, and uncertain-avoidant (Bowlby, 2010).

Most jobs require communication, performing, adaptation, and cooperation. This is why individuals' attachment styles can potentially affect various aspects of work (Mikulincer \& Shaver, 2007). Many relevant studies are based on the conceptualization of attachment using attachment anxiety and attachment avoidance as two orthogonal dimensions (Brennan \& Shaver, 1995; Mikulincer \& Shaver, 2007; Leiter et al., 2015). Brennan and Shaver (1995) derive four attachment styles in adulthood from a combination of these two dimensions. If both dimensions are low, one can talk about a secure style; individuals are satisfied with closeness and mutual dependence, and they rely on support. An anxiety style (high anxiety and low avoidance) rep- 
resents a lack of security, a strong need for closeness, a concern for relationships, and a fear of rejection. An avoidant style means a lack of security, compulsive self-reliance, and a preference for emotional distancing from others. Finally, a disorganized style exhibits a high degree of anxiety and avoidance (Brennan \& Shaver, 1995).

Individuals with insecure attachment orientations (avoidance and anxiety) report greater burnout, and this negative state translates into lower levels of life satisfaction (Reizer, 2015). Compared to attachment avoidance, attachment anxiety has a higher (positive) correlation with negative aspects of working life and a higher (negative) correlation with positive aspects (Leiter et al., 2015). Richards and Schat (2011) discovered that employees with an insecure anxiety attachment style were prone to seeking higher instrumental and emotional support, while avoidant individuals were less likely to do so.

The relationship between supervisors and employees is characterized by a certain specificity. Its particularity is provided by its asymmetry, as "both the leader and the follower bring different expectations and interpretive frameworks to the relationship" (Harms, 2011, p. 293) along with the fact that this relationship is target-specific in its nature. The supervisor-employee relationship tends to replicate the caregiver-child attachment model (Harms, 2011), whereas the supervisor, as a formal authority, also represents a special target of commitment at work. Therefore, it is important to pay research attention to how both of these variables (attachment model and commitment) affect work behavior.

\section{Current Study}

The current research is based on two conceptualizations of supervisory commitment: 1) affective commitment as defined by Meyer and Allen (1991, p. 67) ("the employee's attachment to, identification with, and involvement in [...]"), and 2) commitment using Klein et al.'s unidimensional and target-free concept, reflecting dedication, volition, and responsibility to any workplace target. As mentioned in the introduction, several studies have documented the relationship between citizenship behavior and affective organizational commitment (Allen et al., 2011; Cetin et al., 2015; Meyer et al., 2002) and between citizenship behavior and affective commitment to supervisor (ACS) as well (Askew et al., 2013; Vandenberghe et al., 2017; Vandenberghe et al., 2004). The proximity and regular interaction between employees and supervisors may cause an employee's attachment to their supervisor to become an important factor in positive work behavior. For instance, it has been revealed that employees' commitment to management, supervisors, and workgroups provides a better explanation for variance in job satisfaction and turnover intention than the commitment to organizations in itself (Becker et al., 1996). Some authors report a "supervisor effect," which means that affective commitment to the supervisor has an important effect on the commitment to other objects at work including organization (Askew et al., 2013). Klein et al. (2014) created a new instrument to study their reconceptualized model of commitment: Klein et al.'s Unidimensional Target-free Measure (KUT). Compared to the TCM questionnaire from Meyer and Allen, KUT is narrower in scope, being based on a more exact definition and covering only a certain type of bond in the workplace (Klein et al., 2014). At the same time, a narrower and more linear item formulation can lead to explaining less or differentially the variance in commitment outcomes compared to previous commitment measures (Klein et al., 2014). Klein et al. (2014) demonstrated that compared to the TCM affective scale, 
KUT predicted less variance in identification (the organization and team as a target), satisfaction, and turnover intention, but not in extra-role behavior. The lack of literature led the present authors to the question of whether exploring the relationship between OCB and supervisory commitment would provide similar results when using Klein et al.'s target-free commitment model in comparison with the affective supervisor commitment model.

Working behavior is "an inherently relational act" (Blustein, 2011, p.1), and internal and external relational factors shape the working context. In this relational perspective, the Attachment Personality Theory, suggesting that internal working models may have an impact on relational behavior at work (Mikulincer \& Shaver, 2007), provides an appropriate framework for research concerning employee behavior. OCB is more interpersonal in nature than other aspects of job performance (Harms, 2011), reflects interrelationship tendencies, and has a correlation with personal attachment-related dimensions (Desivilya et al., 2007; Mikulincer \& Shaver, 2007). As mentioned in the introduction, several studies documented strong negative correlations between attachment avoidance, attachment anxiety, and positive aspects of working life (Leiter et al., 2015; Reizer, 2015). According to Hazan and Shaver (1990), the experiences of anxious individuals are affected by the chronic hyperactivation of their attachment needs and goals. A person who has high attachment avoidance distrusts other people, is compulsively self-reliant, avoids intimacy in close relationships, and usually prefers to do things alone (Mikulincer \& Shaver, 2007). Attachment avoidance represents a strategy for avoiding social interaction and intimacy in a relationship, a preference to do things alone, and a withdrawal from the social field. From the point of view of the application of attachment theory, one can look at followers as chil- dren, who are seeking support from a leader. The need for a stronger and wiser leader reflects the activation of the attachment system in breaking a symbolic bond with a supervisor (Mikulincer \& Shaver, 2007). Like the secure attachment between a child and a parent, the bond between a leader and employee has positive consequences; increases self-esteem and self-confidence; and increases autonomy, initiative, and motivation (Popper \& Mayseless, 2003; Mayseless \& Popper, 2007). It can be assumed that the degree of commitment to a supervisor, as a predictor of altruistic prosocial behavior expressed by the degree of organizational citizenship, is modified by the activated attachment model of the employee.

To capture a more complete relational picture of working, the second objective of the present research was to examine how personal attachment dimensions (anxiety and avoidance) moderate the relationship between supervisory commitment and OCB (Figure 1). This goal embodies the authors' contribution to the research into supervisory commitment and can bring a new perspective to this topic.

The following three hypotheses were thus articulated:

Hypothesis 1: Affective commitment to the supervisor (ACS) and commitment to supervisors measured by the KUT method will both be in a positive relationship with organizational citizenship behavior.

Hypothesis 2: A high degree of attachment anxiety significantly and negatively moderates the strength of association between commitment to supervisors and organizational citizenship behavior. (A high level of attachment anxiety decreases the positive impact of commitment to supervisors on the level of OCB.)

Hypothesis 3: A high degree of attachment avoidance significantly and negatively moderates the strength of association between the commitment to supervisors and organizational citizenship behavior. (A high level of 


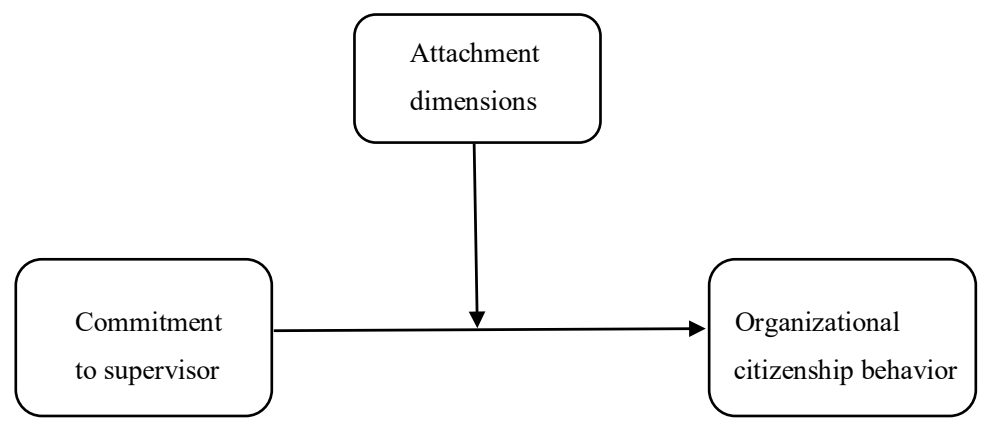

Figure 1 Moderating model

attachment avoidance decreases the positive impact of commitment to supervisors on the level of OCB.)

\section{Methods}

\section{Samples and Procedures}

Data were collected using an online questionnaire through social networks and with voluntary participation. A minimum inclusion criterion was used; selected participants indicated that they were in full-time employment for a fixed or indefinite term in a non-managerial position. The sample consisted of 197 respondents working in different professions in both the private and public sectors: 49 (24.9\%) were male and $148(75.1 \%)$ were female; 116 (58.9\%) were single, 62 (31.5\%) were married, and 19 (9.6\%) indicated "other." The age range was from 18 to 60 years, with the average age being 32.12 (SD = 11.13). The minimum tenure was 0.25 years, the maximum was 32 years, and the average tenure was $6.87(S D=9.03)$ years. Most of the respondents (111) were permanent employees, constituting $56.3 \%$ of the sample, while
86 respondents $(43.7 \%)$ were working on a fixed-term contract.

The surveys included written instructions, informed consent, and e-mail addresses where respondents could reach out if they had questions. They were informed that all the collected data was anonymous and would only be used for research purposes. The data collection took place between the beginning of January and the middle of March 2019.

\section{Measures}

\section{The Experiences in Close Relationships Scale}

The Experiences in Close Relationships (ECR) scale was created by Brennan et al. (1998); this self-assessing scale has become one of the most widely used methods to determine adult attachment personality dimensions. It consists of two subscales individually containing eighteen items: the first examines the dimension of anxiety and the second examines the dimension of avoidance. The items are rated on a seven-point Likert scale (1 = strongly disagree to 7 = strongly agree). Some of the items had a reverse scoring. The anxi- 
ety-measuring scale contained items such as "I worry about being rejected or abandoned." The avoidance-measuring scale had statements like "I prefer not to show others how I feel deep down." The items demonstrate a high internal consistency, and there is extensive evidence to support their construct validity. The ECR scale was translated from English into Slovak, and the translation was compared with an existing Czech version (Lečbych \& Pospíšiliková, 2012). The internal reliability of the anxiety scale yielded an alpha score of .906 , while the avoidance scale had an alpha reliability of .831 . The alpha reliability of the anxiety scale indicated by the original authors was .91, and for the avoidance scale it was .94 (Brennan et al., 1998).

\section{The Organizational Citizenship Behavior Scale}

This scale was created by Podsakoff et al., (1990) and measures five dimensions of OCB: altruism, conscientiousness, sportsmanship, civic virtue, and courtesy. It consists of twenty statements describing various forms of behavior in an organization. For example: "I take my job seriously and rarely make mistakes," "I actively attend institution meetings," and "I am willing to stand up to protect the reputation of the institution." Respondents rate the individual statements on a five-point Likert scale ( 1 = strongly disagree to 5 = strongly agree). The present study used a verified Slovak translation (Rošková \& Schraggeová, 2015). LePine et al. (2002) demonstrated that the five dimensions are highly related to one other and the equivalent indicator of OCB. They recommend considering OCB as one construct and avoiding focusing on the specific dimensions. The original internal consistency reliabilities for each of the dimensions ranged from .78 to .92 (Podsakoff et al., 1990). For the purposes of the present study, the overall OCB score was computed by averaging the twenty items: $\alpha=.769$.
Klein et al.'s Unidimensional Target-free Measure

The KUT scale was created by Klein et al. (2014). This scale consists of four questions that are answered using a five-point scale ( 1 = not at all to 5 = extremely). Results have confirmed that this is a valid measure, which provides consistent and comparable data about various relevant foci of workplace commitments. The Czech adaptation provided evidence of the KUT scale's robustness regarding internal consistency as well as content, factor, convergent, discriminant, and incremental validity (Procházka et al., 2019). Based on the proximity of the Czech and Slovak cultural contexts, this validation study can be relied on in the present research. For the purposes of the present research, the items were edited so that respondents could express their commitment to their supervisors. Two of the questions were "How committed are you to your supervisor?" and "How dedicated are you to your supervisor?" Since this scale was originally formulated in English, it first had to be translated into Slovak and then retranslated back into English using an independent translator. An alpha reliability of .815 was established. Depending on the commitment target, Klein et al. (2014) report a reliability of .86-.97 for their scale; in the case of commitment to supervisors, the value is .96 .

\section{The Affective Commitment to Supervisors Scale}

This scale, created by Vandenberghe and Bentein (2009), is a modified version of Meyer, Allen, and Smith's original scale (1993). It consists of six items, including "I feel proud to work with my supervisor," "I feel a sense of respect for my supervisor," and "My supervisor means a lot to me." Two items, including "I 
am not really attached to my supervisor," had a reverse scoring. Respondents rated their agreement with the individual statements on a seven-point Likert scale (1 = strongly disagree to 7 = strongly agree). The scale was translated from English into Slovak and then retranslated back into English to avoid any ambiguities. There was an alpha reliability of .862 . The original reliability indicated $\alpha=$ $.86-.87$.

\section{Statistical Analysis and Procedure}

A statistical analysis of the collected data was carried out in the SPSS Statistics 25 program. Correlation analyses were used to examine the associations among all the study variables. A statistical power analysis was performed using G*Power3 (Faul et al., 2007). To test multiple regression with three predictors, according to Cohen's criteria (Cohen, 1992), a medium effect size was expected with an alpha score $=0.05$ and power $=0.80$. The recommended sample size needed with this effect size was $N=77$. A final sample of $N=197$ would thus provide sufficient power for testing the proposed moderation mod- els. These hypotheses were first tested using Spearman's correlation coefficient, and then the moderating models were calculated using A. F. Hayes' PROCESS for SPSS Version 3.00 (Model 1) (Hayes, 2012).

\section{Results}

Table 1 presents basic descriptive statistics and a correlation analysis.

The correlation analysis (Table 1) showed a significant link between OCB and supervisory commitment; the extent of this relationship was comparable when measured by ACS ( $r=$ $0.260 ; p<0.01)$ and KUT scales $(r=0.276 ; p<$ 0.01 ). In addition, the degree of OCB showed a highly positive correlation with age $(r=0.169$; $p<0.05)$ and a highly negative correlation with the dimension of attachment anxiety ( $r=-0.246 ; p<0.01)$. Attachment avoidance did not have a significant correlation with OCB.

In the next step, A. F. Hayes's PROCESS (Model 1) was used to calculate the moderating models. In the first model, the dependent variable was organizational citizenship behavior, the independent variable was affective

Table 1 Basic statistical measures and correlations

\begin{tabular}{lrrrrcccc}
\hline Scale & \multicolumn{1}{c}{ M } & \multicolumn{1}{c}{ SD } & \multicolumn{1}{c}{ 2. } & \multicolumn{1}{c}{3.} & \multicolumn{1}{c}{4.} & 5. & 6. & 7. \\
\hline 1. Age & 32.12 & 11.13 & $.740^{* *}$ & -.054 & $-.259^{* *}$ & $.169^{*}$ & $-.252^{* *}$ & $-.172^{*}$ \\
2. Tenure & 6.87 & 9.04 & & -.088 & $-.178^{*}$ & .072 & $-.193^{* *}$ & $-.183^{* *}$ \\
3. Avoidance & 3.49 & .83 & & & $.151^{*}$ & -.072 & -.026 & -.024 \\
4. Anxiety & 3.67 & 1.12 & & & & $-.246^{* *}$ & .007 & -.034 \\
5. OCB & 79.94 & 8.38 & & & & & $.260^{* *}$ & $.276^{* *}$ \\
6. KUT & 13.11 & 3.69 & & & & & & $.769^{* *}$ \\
7. ACS & 28.37 & 8.41 & & & & & & \\
\hline
\end{tabular}

Note. OCB = Organizational Citizenship Behavior. KUT = Klein et al.'s Unidimensional Targetfree Commitment to Supervisor. ACS = Affective Commitment to Supervisors.

${ }^{*} p<0.05 ; * *<0.01$ 
commitment to supervisors, and the moderator variable was the dimension of attachment anxiety. Table 2 presents the results of the first moderating model. The whole model was confirmed as significant $(F=11.3087$, $p=.001$ ) with a regressive coefficient of $R^{2}=14.95 \%$. The most important finding was that attachment anxiety was proven to act as a moderator. After introducing the interaction between ACS and attachment anxiety as a variable, the value of the regression coefficient increased by $2.8 \%$. Figure 2 shows that the interaction between the degree of attachment anxiety and commitment to one's supervisor negatively affects OCB. Individuals with a high degree of anxiety had the lowest degree of OCB. This moderating effect is only apparent when the commitment is low or moderate; attachment anxiety does not seem to act as a moderator when there is a high degree of supervisory commitment.

In the second moderating model, the independent variable (commitment to supervisors) was measured by the KUT scale (Table 3). Interestingly, no moderation was confirmed and the interaction between commitment to supervisors and attachment anxiety did not affect the degree of OCB.

Table 2 Moderating model 1: Interaction between affective commitment to supervisors and attachment anxiety in relation to organizational citizenship behavior

\begin{tabular}{lrcccccc}
\hline & coeff & se & $p$ & $R^{2}$ & $F$ & $p$ & $R^{2}$ change \\
\hline Constant & 79.983 & .555 & .000 & $14.95 \%$ & 11.87 & .001 & \\
ACS & .254 & .066 & .0002 & & & & \\
Att. anxiety & -1.898 & .499 & .0002 & & & & \\
ACS x Att. anxiety & .156 & .061 & .0113 & & & & $2.88 \%$ \\
\hline
\end{tabular}

Note. ACS = Affective commitment to supervisors

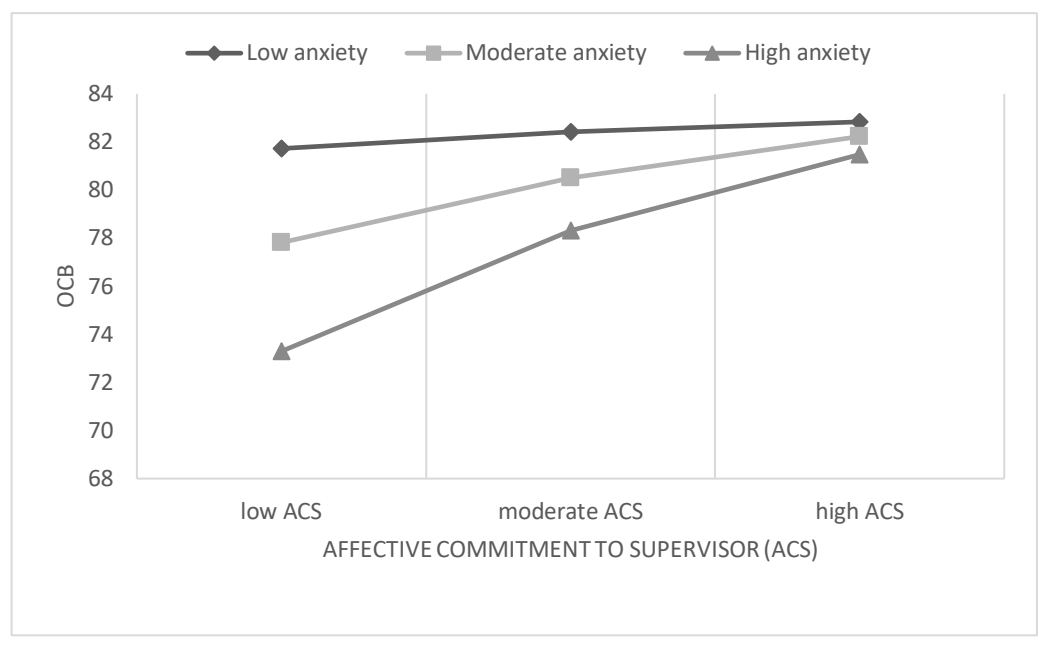

Figure 2 The influence of supervisory commitment on organizational citizenship behavior in relation to attachment anxiety 
In the third examined moderation model, the independent variable was affective supervisory commitment and the moderator variable was attachment avoidance dimension. The whole model was confirmed as significant
$(F=5.16 ; p=.001)$ with a regressive coefficient of $R^{2}=9.60 \%$. The moderation effect of interaction between ACS and attachment avoidance increased the regression coefficient by $2.26 \%$ (Table 4). Individuals with a high de-

Table 3 Moderating model 2: Interaction between supervisory commitment (measured by KUT) and attachment anxiety in relation to organizational citizenship behavior

\begin{tabular}{lrccccc}
\hline & coeff & se & $p$ & $R^{2}$ & $F$ & $p$ \\
\hline Constant & 79.921 & .569 & .001 & $12.48 \%$ & 8.566 & .001 \\
KUT & 0.559 & .154 & .0004 & & & \\
Att. anxiety & -1.914 & .511 & .0002 & & & \\
KUT x anxiety & .192 & .133 & .151 & & & \\
\hline
\end{tabular}

Note. KUT = Klein et al.'s Unidimensional and Target-free Measure

Table 4 Moderating model 3: Interaction between affective commitment to supervisors and attachment avoidance in relation to organizational citizenship behavior

\begin{tabular}{lrcccccc}
\hline & coeff & se & $p$ & $R^{2}$ & $F$ & $p$ & $R^{2}$ change \\
\hline Constant & 79.985 & .575 & .000 & $9.60 \%$ & 5.16 & .001 & \\
ACS & .258 & .079 & .001 & & & & \\
Att. avoidance & -1.06 & .660 & .115 & & & & \\
ACS x avoidance & .189 & .077 & .015 & & & & $2.26 \%$ \\
\hline
\end{tabular}

Note. ACS $=$ Affective Commitment to Supervisors

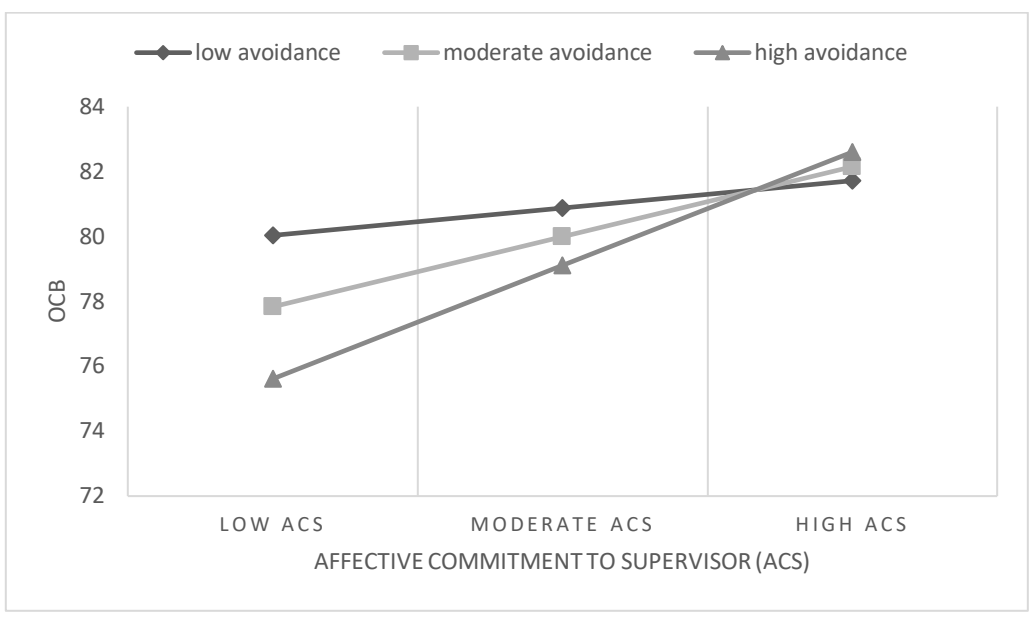

Figure 3 The influence of supervisory commitment on organizational citizenship behavior in relation to attachment avoidance 
gree of avoidance had the lowest degree of OCB. This moderating effect is only apparent when the commitment is low or moderate; when there is a high degree of commitment, the degree of avoidance attachment does not predict the level of OCB (Figure 3).

In the fourth examined model, the independent variable was the commitment to supervisors measured by the KUT scale and the moderator variable was the attachment avoidance dimension. The whole model was confirmed as significant $(F=3.75 ; p=.012)$ with a regressive coefficient of $R^{2}=7.92 \%$ (Table 5). The degree of the explained propor- tion of the variance was smaller than in the previous models. The attachment avoidance dimension was proven to act as a moderator, although there was a $1.68 \%$ increase in the regression coefficient after introducing the interaction between commitment to supervisors and attachment avoidance as a variable. Individuals with a high degree of avoidance had the lowest degree of OCB. This moderating effect is only apparent when the commitment is low; when there is a high degree of commitment, the degree of avoidance attachment does not predict the level of OCB (Figure 4).

Table 5 Moderating model 4: Interaction between commitment to supervisors (measured by KUT) and attachment avoidance in relation to organizational citizenship behavior

\begin{tabular}{lrcccccc}
\hline & coeff & se & $p$ & $R^{2}$ & $F$ & $p$ & $R^{2}$ change \\
\hline Constant & 79.968 & .58 & .000 & $7.92 \%$ & 3.75 & .012 & \\
KUT & .534 & .168 & .001 & & & & \\
Att. avoidance & -1.055 & .686 & .126 & & & & \\
KUT x avoidance & .328 & .164 & .047 & & & & $1.68 \%$ \\
\hline
\end{tabular}

Note. $\mathrm{KUT}=$ Klein et al.'s Unidimensional and Target-free Measure

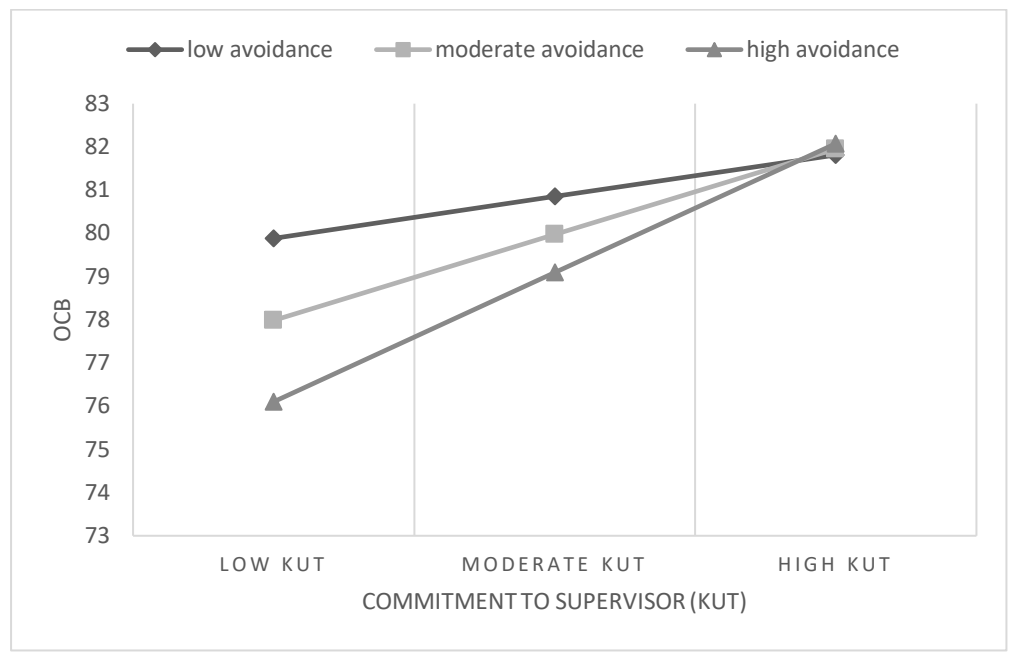

Figure 4 The influence of supervisory commitment on organizational citizenship behavior in relation to attachment avoidance 


\section{Discussion}

The concepts of commitment to supervisor, citizenship behavior and interpersonal attachment models represent the social and psychological aspects of the workplace context, and the ambition of the present study was to indicate their mutual interconnection. Commitment was understood as both an affective bond with supervisors (Vandenberghe et al., 2017; Vandenberghe et al., 2004) and a more narrowly understood, conscious, and voluntary devotion to supervisors (Klein et al., 2012). It was hypothesized that the link between an employee and a supervisor, expressed in terms of the degree of commitment as well as prosocial altruistic behavior (i.e., OCB), can be influenced by unconscious attachment patterns of interactive behavior.

The first research objective was to compare the predictive value of the two scales of supervisory commitment which offer a different perspective on understanding commitment. ACS is a verified scale measuring employees' identification with and dedication to their supervisors, their pride in working with them, and their shared values (Vandenberghe \& Bentein, 2009). The second scale used - KUT - is based on the unidimensional target-free concept that primarily sees commitment as a consciously created volitional bond reflecting responsibility for and dedication to the target of commitment without any contamination with identification, an affective element, or a behavioral intention (Klein et al., 2014). With its four items, the scale asked users to evaluate their own degree of commitment. When reconceptualizing commitment, Klein et al. (2012) tried to differentiate between individual types of workplace bonds by grading them according to the degree of psychological dedication: acquiescence, instrumental bonds, commitment, and identification. They placed commitment higher than instrumental bonds but lower than identification. They defined commitment as "a socially constructed psychological state, differentiated from other bonds in that the individual does not psychologically merge with the target but does make a conscious choice to care about and dedicate him/herself to the target" (Klein et al., 2012, p. 137). They argue that, unlike their target-free concept, affective commitment is "defined, in part, in terms of identification," which they consider "a distinct bond type" (p. 138). The present study found a high correlation between ACS and KUT to the supervisor as a target $(r=0.769)$, which confirms that the KUT method is a valid tool to measure a similar (but not identical) construct as the ACS scale. It can be stated that both measures of commitment more or less show the same relationship to civic behaviors in organization. This means that organizationally beneficial actions and behaviors, which cannot be enforced on the basis of formal role obligations, occur significantly more in employees with a higher commitment rate to their supervisor. In the regression moderation models, the predictive value of both commitment measures, before adding the interaction variable between commitment and the attachment dimension, was different. The predictive value expressed by the $b$ coefficient was considerably higher for commitment measured by the KUT $(b=0.559)$ scale when compared with affective commitment scale measures $(b=$ 0.254). Klein et al. (2014) state that while KUT (as a narrower concept) can predict less variance in comparison with prior commitment conceptualizations, this is not necessary for key commitment outcomes such as extra-role civic behavior. These results similarly suggest that the impact of commitment on OCB, in terms of Klein et al.'s reconceptualization, is more significant. The present results are consistent with previous studies, which indicated 
a positive relationship between citizenship behavior and commitment to supervisors (Askew et al., 2013; Becker et al., 1996; Gregersen, 1993), noting that, similarly to organizational commitment, supervisory commitment has a positive impact on extra-role civic behavior (Allen et al., 2011; Cetin et al., 2015; Meyer et al., 2002). This result is especially important given that organizations are no longer the most important foci of commitment as a result of high-labor market dynamism and the proliferation of various alternative employment forms and options.

The next objective was to examine the influence of personal attachment-related variables (anxiety and avoidance) that can moderate the relationship between commitment to supervisors and citizenship behaviors. Studies investigating personal predispositions and work behaviors used to focus mainly on the Big Five model (e.g., Panaccio \& Vandenberghe, 2012). The initial hypothesis was formulated so that personal dimensions derived from attachment personality models might provide greater insight into the mechanisms behind workplace attitudes and job behaviors. Studies conducted by Hazan and Shaver (1990), Harms (2011), Mikulincer and Shaver (2007), Leiter et al. (2015), and Reizer (2015) led to the assumption that individuals with a higher degree of anxiety attachment will constantly worry about their relationships and how others perceive them, and that these preoccupations will also manifest themselves in day-to-day behavior. Meanwhile, individuals with a higher degree of avoidance will experience a lower degree of OCB due to their inability to engage in relationships with co-workers and their emotional withdrawal from social areas at work. The dimension of attachment anxiety in the present research was found to have a considerable moderating impact on the relationship between ACS and the degree of OCB. This means that no- table differences in organizational citizenship were found in the case of employees who felt the same amount of affective commitment to their supervisors but experienced either high or low anxiety in their internal anxiety attachment dimension. This moderating effect also applied to employees experiencing a low or moderate degree of supervisory commitment. However, these differences disappeared when the degree of ACS was high and the degree of OCB remained unaffected (see Figure 2). This meant that individuals experiencing more anxiety and mistrust in their relationships and perceiving a low degree of ACS tended to engage less in citizenship behavior. Individuals scoring low in attachment anxiety (one can expect that they have a secure internal attachment style) exhibit OCB to a high degree regardless of their commitment to supervisors. They are independent, secure, and not worried about relationships; they are open to acting helpfully toward other people representing the organization. Conversely, individuals who are unsure and worried about themselves, and who feel less committed to their supervisors, participate less in prosocial work activities. Identification with one's supervisor plays an especially important role in the case of individuals experiencing a higher degree of self-doubt and interactional uncertainty.

In this sense, the present study agrees with Popper and Maysles's (2003) assertion that a good (transformational) leader "can play an important role in providing corrective experiences for insecure followers" (p. 9). If their commitment to the supervisor is high, anxious individuals show a comparable degree of citizenship to individuals who experience less internal attachment anxiety. Building a secure trustful relationship with one's supervisor can create a protective factor against personal uncertainties and can increase one's willingness and motivation to engage in voluntary activi- 
ties that are beneficial for teams and organizations.

Interestingly, this result only arose when the commitment was measured using the ACS scale. When using the moderating model with an independent variable measured by the KUT method, the moderating influence of anxiety attachment dimension did not appear. Commitment to supervisors and attachment anxiety acted as two independent predictors, whose interaction did not affect citizenship behavior at work. This result can be explained by the different philosophies behind the formulation of the items. The KUT concept defines commitment more narrowly as a volitional and conscious psychological bond toward a particular target. The affective commitment measure, expressing a higher degree of affective attitude to supervisors and partially overlapping with identification, appeared to interact with interpersonal anxieties and worries with a considerable effect on the degree of citizenship behavior.

While the dimension of attachment anxiety had an impact on OCB as an independent predictor, the situation for attachment avoidance dimension was rather different. The dimension of attachment avoidance did not show a direct impact on the rate of OCB, or a significant relationship to commitment to supervisors, but it did prove to be an important moderator in the interaction with the commitment to supervisors. These results provide support for the interaction hypothesis, confirming Barron and Kenny's basic considerations related to moderation analysis, that "[...] it is desirable that the moderator variable be uncorrelated with both the predictor and the criterion (the dependent variable) to provide a clearly interpretable interaction term" (Barron \& Kenny, 1986, p. 1184). The results of the moderation effects indicate that attachment avoidance does not cause negative outcomes on work behaviors alone as an independent factor, only doing so in interac- tion with a perceived commitment to supervisors. Employees scoring high in attachment avoidance can be characterized by a distrust of other people, self-reliance, a preference to do things alone, and an avoidance of social interaction at work (Brennan \& Shaver, 1995; Harms, 2011; Mikulincer \& Shaver, 2007; Leiter et al., 2015). These characteristics alone do not reduce the extra-role of prosocial behavior, but a reduction does occur when they are in interaction with low levels of voluntary involvement (commitment) to supervisors. Conversely, building a secure relationship with one's supervisor can create a protective factor against personal distrust, self-reliance, and interpersonal withdrawal, and it can help in voluntary prosocial activities that are beneficial for teams and organizations. The moderation effect of attachment avoidance was significant when using both measurement methods of commitment to supervisors (affective commitment and KUT). It is important not to overestimate these results, as the moderation models did not explain more than eight to fifteen per cent of the variance of the dependent variable. Furthermore, Becker (2016) emphasizes the need to take into consideration changing working conditions and related organizational attachments. It seems unrealistic to expect employees to form longterm bonds to an organization when that organization cannot make such a commitment toward its employees, and this begs the following question: "To what target (supervisor, team, or project) should an employee develop their commitment, and how should the management behave?" The present findings indicated that a supervising employee could be such a relevant target.

\section{Limitations}

There were several limitations to the present research. One of the limitations was the us- 
age of self-evaluating scales where answers can be subjectively skewed. At the same time, the strength of the study was that two methods were used to measure the independent variable of commitment to supervisors, which also confirms the validity of the employed methods.

Another limitation was the cross-sectional design of the research sample, which was obtained through an online survey. On the one hand, this meant an easier availability and faster data collection, but on the other hand it only targeted people who were willing to interact online and who possessed certain computer skills. The size of the sample and the non-random and occasional selection of participants is another study limitation. In addition, the homogeneity of the sample would have been higher if it had been collected, for instance, within a single organization. Future studies with a larger sample size and sufficient power should address the effects of more specific employment.

The last limitation is also a recommendation for further research; supervisors' relationships with employees were not taken into consideration. In the future, the supervisoremployee relationship could be objectivized by examining this relationship from the other side as well. Another topic worth researching in relation to supervisory commitment should focus on understanding the dyadic employee-supervisor relationship, where the compatibility of their thinking about their mutual commitment is concerned (Landry \& Vandenberghe, 2012). Another suggestion for future research is distinguishing between citizenship behavior directed toward individuals and toward organizations (LePine et al., 2002) in relationships with different work-related targets. It is also important to take into account that a significant role in leader-follower interaction is played by the internal attachment working model of the employee as well as by the attachment model with which the supervisor enters (Popper \& Mayseless, 2003). The concept of transformational leadership that compares the role of leaders with a positive parental figure from the point of view of attachment theory provides some inspiration for future research. Transformational leaders increase the followers' autonomy, self-confidence, achievement orientation, self-worth, and creativity (Popper et al., 2000), which in turn has a positive effect on individuals, the teams, and whole organizations.

\section{Conclusions}

The results of the present research support the hypothesis that there is a correlation between commitment to supervisors and the degree of organizational citizenship behavior. The predictive value of commitment was confirmed by using the ACS scale and KUT method. The results support the hypothesis of moderation effects of attachment anxiety and attachment avoidance dimensions on the relationship between supervisory commitment and organizational citizenship behavior. However, the moderation analysis showed some differences depending on which scale and concept behind it was being used. Affective commitment to supervisor interacted with the dimension of attachment anxiety; when a supervisory commitment was low or moderate, anxiety decreased one's engagement in citizenship behavior. By contrast, the moderating model indicated that when using the KUT method there was no interaction between them; commitment to supervisors and anxiety merely acted as independent predictors. The moderating role of the attachment avoidance dimension was observed by using both commitment measures, although the interaction effect between supervisory commitment and attachment avoidance only accounted for less than three per cent of the 
variance. The results suggest that employees with a secure sense of attachment are more prosocial and beneficial to the organization regardless of their commitment to supervisors; their prosocial behavior is independent of their supervisors. On the contrary, individuals with a high degree of attachment avoidance and anxiety showed a higher rate of OCB only in interaction with a high commitment to a supervisor. The results suggest the importance of building a leader-follower relationship that can provide a compensatory role for employees with an uncertain internal attachment style. Individuals who are highly committed to supervisors can become very useful contributors toward an organization's prosperity.

\section{Acknowledgement}

The research was supported by Slovak Research Agency VEGA: 1/0273/18

\section{Authors' ORCID}

Milica Schraggeová

https://orcid.org/0000-0002-9679-4663

Zuzana Stupková

https://orcid.org/0000-0001-9248-6332

\section{References}

Allen, R. S., Evans, W. R., \& White, Ch. S. (2011). Affective organizational commitment and Organizational Citizenship Behavior: Examining the relationship through the lens of equity sensitivity. Organization Management Journal, 8, 218-228. https://doi.org/10.1057/omj.2011.40

Askew, K., Taing, M. U., \& Johnson, R. E. (2013). The effects of commitment to multiple foci: An analysis of relative influence and interactions. Human Performance, 26(3), 171-190. https:// doi.org/10.1080/08959285.2013.795571

Barkham, M., \& Hardy, G. (1994). The relationship between interpersonal attachmentstyleand work difficulties. Human Relations, 47(3), 263-281. https://doi.org/10.1177/001872679404700302
Baron, R. M., \& Kenny, D. A. (1986). The moderator-mediator variable distinction in social psychological research: Conceptual, strategic, and statistical considerations. Journal of Personality and Social Psychology, 51(6), 1173-1182.

Becker, H. S. (1960). Notes on the concept of commitment. The American Journal of Sociology, 66, 32-40.

Becker, T. E. (2016). Multiple foci of workplace commitments. In J. P. Meyer, The Handbook of Employee Commitment (pp. 43-55). Northampton, MA: Elgar Publishing.

Becker, T. E., Billings, R. S., Eveleth, D. M., \& Gilbert, N. L. (1996). Foci and bases of employee commitment: Implications for job performance. The Academy of Management Journal, 39(2), 464-482.

Blau, G. (2003). Testing for a four-dimensional structure of occupational commitment. Journal of Occupational and Organizational Psychology, 76(4), 469488. https://doi.org/10.1348/096317903322591596

Blustein, D. L. (2011). A relational theory of working. Journal of Vocational Behavior, 79, 1-17. https://doi.org/10.1016/i.jvb.2010.10.004

Bolino, M. C., \& Turnley, W. H. (2003). Going the extra mile: Cultivating and managing employee citizenship behavior. Academy of Management Executive, 17, 60-71. https://dx.doi.org/10.5465/AME.2003.10954754

Bowlby, J. (2010). Attachment and loss - Attachment (Müller, Trans.) Praha: Portál, s.r.o. (Chatto $\&$ Windus, an imprint of Random House, London, 1969). ISBN 978-80-7367-670-4.

Brennan, K. A., Clark, C. L., \& Shaver, P. R. (1998). Self-report measurement of adult romantic attachment: An integrative overview. In J. A. Simpson \& W. S. Rholes (Eds.), Attachment Theory and Close Relationships (pp. 46-76). New York: Guilford Press.

Brennan, K. A., \& Shaver, P. R. (1995). Dimensions of adult attachment, affect regulation, and romantic relationship functioning. Personal and Social Psychology, 21, 267-283. https://doi. org $/ 10.1177 / 0146167295213008$

Cetin, S., Gürbüz, S., \& Sert, M. (2015). A meta-analysis of the relationship between organizational commitment and organizational citizenship behavior: Test of potential moderator variables. Employee Responsibilities and Rights Journal, 27(4), 281-303. https://doi.org/10.1007/s10672-015-9266-5 
Chen, Z. X., Tsui, A. S., \& Farh, J.-L. (2002). Loyalty to supervisor vs. organizational commitment: Relationships to employee performance in China. Journal of Occupational and Organizational Psychology, 75, 339-356. https://doi.org/10.1348/096317902320369749

Cheng, B.-S., Jiang, D. Y., \& Riley, J. H. (2003). Organizational commitment, supervisory commitment, and employee outcomes in the Chinese context: Proximal hypothesis or global hypothesis? Journal of Organizational Behavior, 24, 313-34. https:// doi.org/10.1002/job.190

Chughtai, A. A. (2013). Linking affective commitment to supervisor to work outcomes. Journal of Managerial Psychology, 28(6), 606-627. https:// doi.org/10.1108/JMP-09-2011-0050

Cohen, J. A. (1992). Power primer. Psychological Bulletin, 112(1), 155-159. https://doi.org/10.1037/0033$\underline{2909.112 .1 .155}$

Cohen, A., \& Liu, Y. (2011). Relationships between InRole performance and individual values, commitment, and OCB among Israeli teachers. International Journal of Psychology, 46(4), 271-287. https:// doi.org/10.1080/00207594.2010.539613

Desivilya, H. S., Sabag, Y., \& Ashton, E. (2007). Prosocial tendencies in organizations. The role of attachment styles and organizational justice in shaping Organizational Citizenship Behavior. International Journal of Organizational Analysis, 14(1), 22-42. https://doi.org/10.1108/10553180610739731

Eisenberger, R., Stinglhamber, F., Vandenberghe, C., Sucharski, I. L., \& Rhoades, L. (2002). Perceived supervisor support: Contributions to perceived organizational support and employee retention. Journal of Applied Psychology, 87(3), 565-573. https:// doi.org/10.1037/0021-9010.87.3.565

Faul, F., Erdfelder, E., Lang, A. G., \& Buchner, A. (2007). G*Power 3: A flexible statistical power analysis program for the social, behavioral, and biomedical sciences. Behavior Research Methods, 39(2), 175191. https://doi.org/10.3758/BF03193146

Gregersen, H. B. (1993). Multiple commitments at work and extra-role behavior during three stages of organizational tenure. Journal of Business Research, 26, 31-47. https://doi.org/10.1016/01482963(93)90041-M

Goulet, L. R., \& Singh, P. (2002). Career commitment: A reexamination and an extension. Journal of Vocational Behavior, 61, 73-91. https:// doi.org/10.1006/jvbe.2001.1844
Harms, P. D. (2011). Adult attachment styles in the workplace. Human Resource Management Review, 21, 285-296. https://doi.org/10.1016/i. hrmr.2010.10.006

Hayes, A. F. (2012). PROCESS: A versatile computational tool for observed variable mediation, moderation, and conditional process modeling. Retrieved from http://www.afhayes.com/public/process2012.pdf

Hazan, C., \& Shaver, P. R. (1990). Love and work: An attachment - theoretical perspective. Journal of Personality and Social Psychology, 59, 270-280. https://doi.org/10.1037/0022-3514.59.2.270

Jaros, S. (2007). Measurement issues in the Meyer and Allen Model of organizational commitment. ICFAI Journal of Organizational Behavior, 6, 7-25.

Jaros, S. (2017). A critique of normative commitment in management research. Management Research Review, 40(5), 517-537. https://doi. org/10.1108/MRR-08-2016-0200

Keller, K. L. (2003). Strategic brand management: Building, measuring, and managing brand equity. Prentice-Hall. New York. NY. 788 p. ISBN 9780131006706

Klein, H. J., Cooper, J. T., Molly, J. C., \& Swanson, J. A. (2014). The assessment of commitment: Advantages of a unidimensional, target-free approach. Journal of Applied Psychology, 99(2), 222-238. https://doi.org/10.1037/a0034751

Klein, H. J., Molloy, J. C., \& Brinsfield, C. T. (2012). Reconceptualizing workplace commitment to redress a stretched construct: Revisiting assumptions and removing confounds. Academy of Management Review, 37(1), 130-151. https:// doi.org/10.5465/amr.2010.0018

Ko, J. W., Price, J. L., \& Mueller, C. W. (1997). Assessment of Meyer and Allen's Three-Component Model of organizational commitment in South Korea. Journal of Applied Psychology, 82, 961-973. https://doi.org/10.1037/0021-9010.82.6.961

Landry, G., Panaccio, A., \& Vandenberghe, C. (2010). Dimensionality and consequences of employee commitment to supervisors: A two-study examination. The Journal of Psychology, 144(3), 285-312. https://doi.org/10.1080/00223981003648302

Landry, G., \& Vandenberghe, C. (2012). Relational commitments in employee-supervisor dyads and employee job performance. The Leadership Quar- 
terly, 23, 293-308. https://doi.org/10.1016/i.leaqua.2011.05.016

Landry, G., Vandenberghe, C., \& Ayed, A. K. B. (2014). Supervisor commitment to employees: Does agreement among supervisors' and employees' perceptions matter? The Leadership Quarterly, 25, 885-900. https:// doi.org/10.1016/i.leaqua.2014.07.008

Lečbych, M., \& Pospišiliková, K. (2012). Česká verze škály Experiences in Close Relationships (ECR): Pilotní studie posouzení vztahové vazby $v$ dospělosti. [The Czech version of the Experience in Close Relationships (ECR) scale: A pilot study of assessment of attachment in adulthood]. E-psychologie, 6(3). http://e-psycholog.eu/pdf/lecbych-pospisilikova.pdf

Leiter, M. P., Day, A., \& Price, L. (2015). Attachment styles at work: Measurement, collegial relationships, and burnout. Burnout Research, 2, 25-35. https://doi.org/10.1016/i.burn.2015.02.003

LePine, J. A., Erez, A., Johnson, D. E. (2002). The nature and dimensionality of Organizational Citizenship Behavior: A critical review and meta-analysis. Journal of Applied Psychology, 87, 52-65. https:// doi.org/10.1037/0021-9010.87.1.52

Mayseless, O., \& Popper, M. (2007). Reliance on leaders and social institutions: An attachment perspective. Attachment \& Human Development, 9(1), 7393. https://doi.org/10.1080/14616730601151466

McGee, G. W., \& Ford, R. C. (1987). Two (or more?) dimensions of organizational commitment: $\mathrm{Re}$ examination of the affective and continuance commitment scales. Journal of Applied Psychology, 72, 638-641. https://doi.org/10.1037/0021. $\underline{9010.72 .4 .638}$

Mercurio, Z. A. (2015). Affective commitment as a core essence of organizational commitment: An integrative literature review. Human Resource Development Review, 1-26. https://doi. org/10.1177/1534484315603612

Meyer, J. P. (2009). Commitment in a changing world of work. In H. J. Klein, T. E. Becker, \& J. P. Meyer (Eds.), SIOP organizational frontiers series. Commitment in organizations: Accumulated wisdom and new directions (pp. 37-68). Routledge/Taylor \& Francis Group.

Meyer, J. P., \& Allen, N. J. (1991). A three component conceptualization of organizational commitment. Human Resource Management Review, 1, 61-89. https://doi.org/10.1016/1053-4822(91)90011-Z
Meyer, J. P., Allen, N. J., \& Smith, C. A. (1993). Commitment to organizations and occupations: Extension and test of a three-component conceptualization. Journal of Applied Psychology, 78, 538-551. https://doi.org/10.1037/0021-9010.78.4.538

Meyer, J. P., \& Herscovitch, L. (2001). Commitment in the workplace. Toward a general model. Human Resource Management Review, 11, 299-326. https://doi.org/10.1016/S1053-4822(00)00053-X

Meyer, J. P., Stanley, D. J., Herscovitch, L., \& Topolnytsky, L. (2002). Affective, continuance, and normative commitment to the organization: A Meta-analysis of antecedents, correlates, and consequences. Journal of Vocational Behavior, 61, 2052. https://doi.org/10.1006/ivbe.2001.1842

Mikulincer, M., \& Shaver, P. R. (2007). Attachment in adulthood. Structure, dynamics and change. NY, London, The Guilford Press.

Morrison, E. (1994). Role definitions and Organizational Citizenship Behavior: The importance of the employees' perspective. Academy of Management Journal, 37, 1543-1567. https://doi.org/10.2307/256798

Mowday, R. T., Steers, R. M., \& Porter, L. W. (1979). The measurement of organizational commitment. Journal of Vocational Behavior, 14, 224-247. https://doi.org/10.1016/0001-8791(79)90072-1

Organ, D. W. (1997). Organizational citizenships behavior: It's construct cleanup time. Human Performance, 10, 85-97. https://doi.org/10.1207/ s15327043hup1002 2

Organ, D. W. (1988). Issues in organization and management series. Organizational citizenship behavior: The good soldier syndrome. Lexington Books/D. C. Heath and Com. ISBN-13: 9780669117882

Organ, D. W., Podsakoff, P. M., \& MacKenzie, S. B. (2006). Organizational Citizenship Behavior: Its nature, antecedents, and consequences. Personnel Psychology, 59, 484-487. https://doi. org/10.1111/j.1744-6570.2006.00043 9.x

Panaccio, A., \& Vandenberghe, C. (2012). Five-factor model of personality and organizational commitment: The mediating role of positive and negative affective states. Journal of Vocational Behavior, 80, 647-658. https://doi. org/10.1016/i.jvb.2012.03.002

Podsakoff, P. M., MacKenzie. S. B., Moorman, R. H., \& Fetter, R. (1990). Transformational leader behaviors and their effects on followers' trust in leader, 
satisfaction, and Organizational Citizenship Behaviors. Leadership Quarterly, 1, 107-142. https://doi. org/10.1016/1048-9843(90)90009-7

Podsakoff, P. M., \& MacKenzie, S. B. (1997). Performance: A review and suggestion for future research. Human Performance, 10(2), 133-151. https://doi.org/10.1207/s15327043hup1002 5

Podsakoff, P. M., \& MacKenzie, S. B., Paine, J. B., \& Bachrach, D. G. (2000). Organizational citizenship behaviors: A critical review of the theoretical and empirical literature and suggestions for future research. Journal of Management, 26(3), 513-563. https://doi.org/10.1177/014920630002600307

Podsakoff, N. P., Whiting, S. W., Podsakoff, P. M., \& Blume, B. D. (2009). Individual- and organizational-level consequences of organizational citizenship behaviors: A meta-analysis. Journal of Applied Psychology, 94(1), 122-141. https://doi.org/10.1037/a0013079

Popper, M., \& Mayseless, O. (2003). Back to basics: Applying a parenting perspective to transformational leadership. The Leadership Quarterly, 14(1), 41-65. https://doi.org/10.1016/S1048-9843(02)00183-2

Popper, M., Mayseless, O., \& Castelnovo, O. (2000). Transformational leadership and attachment. The Leadership Quarterly, 11, 267-289. https:// doi.org/10.1016/S1048-9843(00)00038-2

Procházka, J., Židlická, A., Cígler, H., Vaculík, M., \& Klein, H. J. (2019). The Czech adaptation of the Klein et al.'s unidimensional target-neutral scale of commitment. Business Administration and Management, XXII(4), 52-66. https://doi.org/10.15240/tul/001/2019-4-004

Reichers, A. E. (1985). A review and reconceptualization of organizational commitment. The Academy of Management Review, 10(3), 465476. https://doi.org/10.2307/258128

Reizer, A. (2015). Influence of employees' attachment styles on their life satisfaction as mediated by job satisfaction and burnout. The Journal of Psychology, 149(4), 356-377. https://doi.org/10 $.1080 / 00223980.2014 .881312$

Richards, D. A., \& Schat, A. C. (2011). Attachment at (not to) work: Applying attachment theory to explain individual behavior in organizations. Journal of Applied Psychology, 96(1), 169-182. https://doi.org/10.1037/a0020372

Riketta, M., \& Van Dick, R. (2005). Foci of attachment in organizations: A meta-analytic comparison of the strength and correlates of workgroup versus organizational identification and commitment. Journal of Vocational Behavior, 67(3), 490-510. https:// doi.org/10.1016/j.jvb.2004.06.001

Rošková, E., \& Schraggeová, M. (2015). Leader-member exchange a organizačné občianske správanie. [Leader-member exchange and organizational citizenship behavior]. Psychologica, 43, 115-126.

Solinger, O. N., van Olffen, W., \& Roe, R. A. (2008). Beyond the Three-Component Model of organizational commitment. Journal of Applied Psychology, 93, 70-83. https://doi.org/ 10.1037/0021. $\underline{9010.93 .1 .70}$

Vandenberghe, C., \& Bentein, K. (2009). A closer look at the relationship between affective commitment to supervisors and organizations and turnover. Journal of Occupational and Organizational Psychology, 82, 331348. https://doi.org/10.1348/096317908X312641

Vandenberghe, C., Bentein, K., \& Panaccio, A. (2017). Affective commitment to organizations and supervisors and turnover: A role theory perspective. Journal of Management, 43, 2090-2117. https://doi.org/10.1177/0149206314559779

Vandenberghe, C., Bentein, K., \& Stinglhamber, F. (2004). Affective commitment to the organization, supervisor, and work group: Antecedents and outcomes. Journal of Vocational Behavior, 64, 47-71. https://doi.org/10.1016/S0001-8791(03)00029-0

Van Rossenberg, Y. G. T., Klein, H. J., Asplund, K., Bentein, K., Breitsohl, H., Cohen, A., Cross, D., de Aguiar Rodrigues, A. C., Duflot, V., Kilroy, S., Ali, N., Rapti, A., Ruhle, S., Solinger, O., Swart, J., \& Yalabik, Z. Y. (2018). The future of workplace commitment: Key questions and directions. European Journal of Work and Organizational Psychology, (Online), 1-16. https://doi.org/1 $\underline{0.1080 / 1359432 X .2018 .1443914}$

Van Steenbergen, E. F., \& Ellemers, N. (2009). Feeling committed to work: How specific forms of work-commitment predict work behavior and performance over time. Human Performance, 22, 410-431. https://doi.org/10.1080/08959280903248385

Wang, C. (2010). An empirical study of the performance of university teachers based on organizational commitment, job stress, mental health and achievement motivation. Canadian Social Science, 6(4), 127-140.

Williams, L. J., \& Anderson, S. E. (1991). Job satisfaction and organizational commitment as predictors of organizational citizenship and in-role behaviors. Journal of Management, 17(3), 601-617. https://doi. org/10.1177/014920639101700305 